Annals of International Medical and Dental Research

E-ISSN: 2395-2822 | P-ISSN: 2395-2814

Vol-8, Issue-2 | March-April 2022

DOI: 10.53339/aimdr.2022.8.2.24

Page no- 180-191 | Section- Research Article (Otolaryngology)

\title{
Mitral Annular Calcification Detected by Transthoracic Echocardiography is a Marker for High Prevalence and Severity of Angiographically Proven Coronary Artery Disease
}

\author{
Md Durul Hoda1*, Chaudhury Meshkat Ahmed ${ }^{2}$, Harisul Hoque ${ }^{3}$, A.K.M. Azad Hossain ${ }^{4}$, Md. \\ Emran Hossain ${ }^{5}$, Sabina Hashem ${ }^{6}$, Nilufar Fatema ${ }^{7}$
}

1Assistant Professor, Department of Cardiology, Shaheed Tazuddin Ahmad Medical College, Gazipur, Bangladesh.

Email: durulhoda10@yahoo.com

Orcid ID: 0000-0003-1233-1416.

2Professor, Department of Cardiology, Bangabandhu Sheikh Mujib Medical University, Dhaka. Email: meshkatbsmmu@gmail.com

Orcid ID: 0000-0001-8701-2167

3Professor, Department of Cardiology, Bangabandhu Sheikh Mujib Medical University, Dhaka. Email: harishoque@gmail.com

Orcid ID: 0000-0002-8079-2153

4Assistant Professor, Department of Cardiology, Mugda Medical College, Dhaka, Bangladesh. Orcid ID: 0000-0002-5349-4839

${ }^{5}$ Assistant Professor, Department of Cardiology, Chattogram Medical College \& Hospital, Chattogram, Bangladesh. Email: dr.imran01818161822@gmail.com, Orcid ID: 00000002-2583-5501

6Professor, Department of Cardiology, National Institute of Cardiovascular diseases (NICVD), Dhaka. Email: dr.sabinahashem25@gmail.com, Orcid ID: 0000-0002-0465-0583

7Consultant, Department of Cardiology, Bangabandhu Sheikh Mujib Medical University, Dhaka. Email: nilufar.fatema@gmail.com, Orcid ID: 0000-0002-8226-6771.

${ }^{*}$ Corresponding author

Received: 14 December 2021

Revised: 19 January 2022

Accepted: 01 February 2022

Published: 18 February 2022

\begin{abstract}
Background: MAC was defined as a dense, localized, highly reflective area at the base of the posterior mitral leaflet detected by TTE. Obstructive CAD was defined as either $50 \%$ reduction of the internal diameter of the left main coronary artery or $70 \%$ reduction of the internal diameter of the left anterior descending, right coronary, or left circumflex artery distribution. Objective: The aim of the study was to evaluate the role of echocardiographically detected MAC as a predictor of coronary artery disease (CAD). Material \& Methods: In this prospective, observational, case-control study, coronary angiography was done in 50 patients with MAC and equal number of patients without MAC, detected with transthoracic echocardiography. Analysis was done to observe the association and correlation of MAC with angiographic findings. Results: Mean age of the case control was $55.16 \pm 10.73$ years and control was $49.80 \pm$ 8.84 years. In this study $34 \%$ of patients with MAC and $32 \%$ patients without MAC had single vessel disease, $16 \%$ of patients with MAC and $24 \%$ patients without MAC had double vessel disease, $42 \%$ of patients with MAC and $22 \%$ patients without MAC had triple vessel disease (TVD), $16 \%$ of patients with MAC and $4 \%$ patients without MAC had Left main coronary artery disease and $8 \%$ of patients with MAC and $22 \%$ patients without MAC had no significant CAD.Multivariate analysis shows MAC $(\mathrm{p}=0.049)$ as an independent predictor for coronary artery disease (CAD). Conclusions: Transthoracic echocardiographically detected MAC is an independent predictor of coronary artery disease. The low cost, portable and radiation free nature of the ultrasound approach make MAC an attractive parameter in the ongoing search for the ideal marker of coronary artery disease (CAD).
\end{abstract}

Keywords:- Transthoracic Echocardiography, Mitral Annular Calcification, Angiographically, Coronary, Artery. 
Annals of International Medical and Dental Research

E-ISSN: 2395-2822 | P-ISSN: 2395-2814

Vol-8, Issue-2 | March-April 2022

DOI: 10.53339/aimdr.2022.8.2.24

Page no- 180-191 | Section- Research Article (Otolaryngology)

\section{INTRODUCTION}

Mitral annular calcification (MAC) is a degenerative process of the surrounding fibrous support of the mitral valve. $[1,2,3]$ It is a common condition. A subgroup of the Framingham Heart Study, which consisted of 1197 patients, revealed that MAC was present in $14 \%$ of these patients.[4] In another population- based study, the prevalence of MAC was reported as $13 \% .4$ ] It is more common in women and in people over 70 years old.[2,3] Atherosclerotic disease is characterized by the accumulation of lipid material in the arterial wall resulting from autoimmune and inflammatory mechanisms. [] More than $90 \%$ of these fatty plaques undergo calcification. [6] Vascular calcification is an active, cellmediated process. Vascular smooth muscle cells retain pluripotential capability and can transform into osteoblast-like cells.[7] Mitral annular calcification (MAC) is associated with several cardiovascular disorders and events, including coronary artery disease (CAD), $[1,8,9]$ carotid and aortic atherosclerosis, stroke, heart failure, and atrial fibrillation. MAC has also been shown to be associated with mortality in the Framingham Heart Study and in a study of patients less than 61 years old (Fox et al, 2003). Aronow et al., found that over a period of 39 months patients with MAC were 1.5 times more likely to suffer from cardiovascular events (42\% compared to 28\%).110] Recently, Adler $\mathrm{Ct}$ al, compared the results of coronary catheterization in 165 patients with MAC and 147 age-matched patients without MAC.[11] The two groups were matched for the presence of hypertension and hyperlipidemia and for the indications for catheterization. The study group had significantly more women and diabetic patients, but less smokers. The patients with MAC had a higher incidence of coronary stenosis greater than or equal to $70 \%$ (89\% compared to $75 \%)$, triple vessel disease (45\% compared to $24 \%$ ) and left main coronary artery stenosis greater than or equal to $50 \%$ (13\% compared to $5 \%)$. In a multivariate analysis, MAC was identified as the most substantial single independent predictor for coronary stenosis. These results can explain the previously demonstrated increased risk for cardiovascular events in MAC patients. Calcified plaque in the coronary arteries is a marker of atheromatous-plaque burden and is predictive of future risk of cardiovascular events,[12] which is frequently used in intervention trials, usually assessed with cardiac Computed Tomography or electronbeam tomographs' through coronary-artery calcium (or Agatston) score. A recent consensus conference concluded that a calcification index should be developed, to facilitate the ability of the clinician to diagnose vascular and valvular calcification in order to predict which patients would have adverse cardiovascular outcomes. 113] Echocardiography is a low cost, portable, facile and radiation-free technique with obvious potential to detect and quantify vascular and valvular calcifications. [14] Pathologic studies have shown that in people between the ages of 13 and 39 foam cells were observed on the endothelium of the epicardial coronary arteries, 115$]$ on the ventricular surface of the posterior mitral leaflet and on the aortic aspects of each of the aortic valve cusps. These collections of foam cells represent early atherosclerotic lesions, suggesting that coronary atherosclerosis, MAC, and calcium deposits of-aortic valve in the elderly have a similar etiology.[15] MAC has been found to 
Annals of International Medical and Dental Research

E-ISSN: 2395-2822 | P-ISSN: 2395-2814

Vol-8, Issue-2 | March-April 2022

DOI: 10.53339/aimdr.2022.8.2.24

Page no- 180-191 | Section- Research Article (Otolaryngology)

beassociated with cardiovascular events (myocardial infarction, ventricular fibrillation, sudden cardiac death). Nair et al. found that over an average follow-up period of 4.4 years, the death rate from cardiac etiologies was 15.5 times higher in patients with MAC (31\% compared to 2\%).[16] Aronow et al., found that over a period of 39 months patients with MAC were 1.5 times more likely to suffer from cardiovascular events $(42 \%$ compared to $28 \%$ ).[17] Recently, Adler et al, compared the results of coronary catheterization in 165 patients with MAC and 147 age-matched patients without MAC.1] The two groups were matched for the presence of hypertension and hyperlipidemia and for the indications for catheterization. The study group had significantly more women and diabetic patients, but less smokers. The patients with MAC had a higher incidence of coronary stenbsis greater than or equal to $70 \% \quad(89 \%$ compared to $75 \%)$, triple vessel disease $(45 \%$ compared to $24 \%$ ) and left main coronary artery stenosis greater than or equal to $50 \%$ (13\% compared to $5 \%)$. In a multivariant analysis, MAC was identified as the most substantial single independent predictor for coronary stenosis. Current study was conducted to observe the association of MAC with CAD and the role of trans-thoracic echocardiography to predict the diagnosis and severity of CAD by using MAC as a marker.

\section{MATERIAL AND METHODS}

This was a prospective, observational, casecontrol study, was conducted from January 2008 to October 2009 in the Department of Cardiology, Bangabandhu Sheikh Mujib Medical University, Dhaka. Patients of Ischemic heart disease with or without MAC who were selected for coronary angiography. 50 patients with mitral annular calcification (MAC) were taken as case and control were 50 patients without mitral annular calcification. As the prevalence of IHD is not available in our country, 100 patients (50 cases and 50 controls) were taken arbitrary. Purposive sampling method was followed.Prior to the commencement of this study, the research protocol was approved by the thesis committee (Local Ethical committee). The aims and objectives of the study along with its procedure, alternative diagnostic methods, risks and benefits of this study was explained to the patients in easily understandable local language and then informed consent was taken from each patient. It was assured that all informed and records would be kept confidential and the procedure would be helpful for both the cardiologist and the patients in making rational approach of the case management.Inclusion criteria wereAge between 25 to 75 years, Primary diagnosis of ischemic heart disease with MAC or without MAC.The patients were diagnosed as a case of IHD on the basis of $>1$ of the following criterias:a) Typical history of anginal chest pain, b) Typical ECG changes for unstable stable angina, myocardial infarction;i. ST segment elevation $>1 \mathrm{~mm}$ in 2 contiguous leads, ii. ST segment depression at least $0.5 \mathrm{~mm}$ in 2 contiguous leads, iii. $\mathrm{T}$ wave inversion at least $1 \mathrm{~mm}$ including inverted $\mathrm{T}$ waves in 2 contiguous leads, iv. Presence of $Q$ wave $>0.03$ seconds in width and $>1$ nun in depth in at least 2 contiguous leads (for Old myocardial infarction), c) Cardiac marker;i. Creatinine Kinase (CK)- upper limit of the normal for Stable/Unstable angina and if raised, myocardial infarction, ii. Creatininc Kinase 
Annals of International Medical and Dental Research

E-ISSN: 2395-2822 | P-ISSN: 2395-2814

Vol-8, Issue-2 | March-April 2022

DOI: 10.53339/aimdr.2022.8.2.24

Page no- 180-191 | Section- Research Article (Otolaryngology)

(CK-MB)- upper limit of the normal for Stable/ Unstable angina and if raised, myocardial infarction, iii. Troponin $\mathrm{T}$ or I- greater than upper limit of the normal (Cannon etal., 2001), d) Positive exercise tolerance test (ETT for Stable! Unstable angina, e) Patients present with Acute myocardial infarction unstable angina were taken as a case of Acute Coronary Syndrome (Kimclal.,2004). Exclusion criteria were Patients with rheumatic valvular heart disease, Prosthetic valves, Cardiomyopathy, Unwilling to give informed consent.

\section{Methods of study}

Detailed history, clinical examination and relevant investigation reports of all patients were recorded in pre designed data collection sheet at the beginning of the study. Only those patients who were admitted with diagnosis of CAD with MAC or without MAC and who were selected for Coronary Angiograms were enrolled in the study. Coronary heart disease were diagnosed on the basis of typical chest pain, ECG change, ETT, biochemical marker, the value of $\mathrm{CK}-\mathrm{MB}$ or Troponin $\mathrm{T} \& \mathrm{I}$. Patients who were on anti-ischaemic therapy were advised to continue the drug. Hypertension were considered if the patient is on anti-hypertensive medication at admission or past medical history or that was measured in several occasions after hospitalization period $>140 / 90 \mathrm{~mm}$ of $\mathrm{Hg}$. Diabetes mellitus were considered if the patient was on antidiabetic medication or found to have blood glucose $>126 \mathrm{mg} / \mathrm{dl}$ or Two hours after plasma glucose level $>200 \mathrm{mg}$. Cigarette (Any amount within past 3 years) significant smoking history were defined as $>10$ pack years of cigarette use.

\section{Echocardiographic technique:}

Complete 2 dimensional \& M-mode echocardiography were performed in all patients with the $2.5 \mathrm{MHz}$ transducer of phased-array sector scanner. The 2 dimensional echocardiographic criteria for MAC included an intense echo - producing structure located at the junction of the atrioventricular groove and posterior mitral valve leaflet on the parasternal long axis, apical 4 chamber, or parasternal short axis views. Cardiac valve calcification was defined as the presence of bright echoes of more than $1 \mathrm{~mm}$ on 1 or more cusps of the aortic valve, mitral valve or mitral annulus. The degree of valvular calcification was graded as mild (spot like calcification $<2 \mathrm{~mm}$ thickness and $<5 \mathrm{~mm}$ length), moderate (multiple calcium spots $>2 \mathrm{~mm}$ thickness and $>5 \mathrm{~mm}$ in length) ,or severe (shadowing or extensive calcification of the valvular annulus, the semilunar cusps, or both). All patients were evaluated independently by two cardiologists experts in echocardiography. In case of disaggrement, a third examiner was consulted. The observers who made the diagnosis of MAC were blinded to the presence or absence of CAD. Echocardiographic examination of mitral annular calcification:Complete 2-dimensional, M-mode, Doppler color-flow echocardiographic examinations are needed to perform to evaluate MAC. MAC is defined as the presence of an intense echo-producing structure located at the juncture of the atrioventricular groove and the posterior mitral leaflet by both 2-dimensional and $\mathrm{M}$ mode echocardiographic findings on parasternal and apical views as described previously (Adler et al,1998). Left ventricular 
Annals of International Medical and Dental Research

E-ISSN: 2395-2822 | P-ISSN: 2395-2814

Vol-8, Issue-2 | March-April 2022

DOI: 10.53339/aimdr.2022.8.2.24

Page no- 180-191 | Section- Research Article (Otolaryngology)

mass is calculated according to Devereux and Reichek (1977) and left ventricular hypertrophy was defined as left ventricular mass index $\geq 110 \mathrm{~g} / \mathrm{m} 2$ in women and $\geq 125$ $\mathrm{g} / \mathrm{m} 2$ in men.The TTE criteria for mitral annulus calcification (MAC) included an intense echo-producing structure located at the junction of the atrioventricular groove and posterior mitral leaflet. MAC was quantified from mild to severe, considering its thickness and length.1] Coronary angiography:Cardiac catheterization and angiography was performed by the judkinstechine. Angiographic films were interpreted by the angiographer who had no knowledge of the echocardiographic result. Obstructive CAD was defined as either $50 \%$ of reduction of the internal diameter of the left main coronary artery or $70 \%$ reduction of the internal diameter of the LAD, LCX, RCA artery distribution.

\section{Statistical analysis of data}

A statistical analysis of the results was obtained by using window based computer software devised with Statistical Packages for Social Sciences (SPSS-13) (SPSS mc, Chicago, IL, USA). Categorical data was expressed in percentage or number. Parametric data was expressed in mean \pm SD. Parametric data was evaluated by independent " $\mathrm{t}$ " test and categorical data was evaluated by Chi- square test and Spearman correlation coefficient test. Significance was defined as $\mathrm{p}$ value $<0.05$.

\section{RESULTS}

A total of 100 coronary heart disease (CHD) patients with MAC and without MAC were selected for the study. Of them 50 patients with
MAC were assigned as case group and 50 patients without MAC were control group. The purpose of the study was to see that Mitral annular calcification detected by transthoracic echocardiography is a marker for high prevalence and severity of angiographically proven coronary artery disease. The result obtained from data analysis is documented below. [Table 1] showed mean age of the case patients of MAC group was $55.16 \pm 10.73$ years and control without MAC group was $49.80 \pm$ 8.84 years. $22 \%$ of the cases were within the age group of 45 years, $48 \%$ were between age 45 to 60 years and $30 \%$ were age of $>60$ years. In control group $34 \%$ within the age group of $\mathrm{E}$ 45 years, $56 \%$ were between age 45 to 60 years and $10 \%$ were of $>60$ years. [Figure 1] showed clinically among cases $14(28.0 \%)$ had Stable angina, $8(16.0 \%)$ had Unstable angina, 3 (6.0\%) had Non ST Elevation myocardial infarction, 2 $(4.0 \%)$ had Acute myocardial infarction, 2 $(4.0 \%)$ had Recent myocardial infarction and $21(42.0 \%)$ had Old myocardial infarction. Among controls 18 (36.0\%) had Stable angina, $9(18.0 \%)$ had Unstable angina, $3(6.0 \%)$ had Non ST Elevation myocardial infarction, 4 $(8.0 \%)$ had acute myocardial infarction, 3 $(6.0 \%)$ had Recent myocardial infarction and 13 $(26.0 \%)$ had Old myocardial infarction. [Table 3 ] showed $64 \%$ of cases of MAC group and $66 \%$ of without MAC control group was smoker. There was no significant difference between the two groups $(p=0.834)$. Sixty percent of cases, $52 \%$ of control non MAC group were hypertensive, $48 \%$ of cases and $22 \%$ of control were diabetic and $8 \%$ of cases and $4 \%$ of control had history of renal disease. Diabetes mellitus was significantly higher in the case groups $(p=0.001)$. [Table 4] showed $18 \%$ of cases and none of controls had family 
Annals of International Medical and Dental Research

E-ISSN: 2395-2822 | P-ISSN: 2395-2814

Vol-8, Issue-2 | March-April 2022

DOI: 10.53339/aimdr.2022.8.2.24

Page no- 180-191 | Section- Research Article (Otolaryngology)

history of Hypertensiom, 24\% of cases and 2\% of controls had family history of Diabetes and $26 \%$ of cases and $4 \%$ of controls had family history of CAD. [Table 5] showed among 50 cases, 15 (30.0\%) had mild MAC, 11(22.0\%) moderate and $24(48.0 \%)$ had severe MAC. Table VI showed among 17 patients of SVD $11(73.3 \%)$ were mild, 5 (45.5\%) Moderate and 1 $(4.2 \%)$ had severe MAC. Among 8 patients of DVD 1 (6.7\%) were Mild, 3 (27.2\%) moderate and $4(16.7 \%)$ had severe MAC. Among 21 patients of TVD none was Mild, 2 (18.2\%) Moderate and 19(42.0\%) had severe MAC. Among 4 patients of non significant CAD, $3(20.0 \%)$ without CAD had mild MAC, 1 (9.1\%) had moderate and none had severe MAC.Table VII showed the correlation between the severity of MAC group and severity of coronary artery disease as done by spearman correlation coefficient test. Correlation revels the severity of MAC is significantly related to severity of coronary artery disease. [Table 8] showed multivariate analysis shows MAC as an independent risk factor for coronary artery disease (CAD), but age, Hypercholesterolernia, Smoking, Hypertension and Diabetes do not significantly show as risk factor.Table IX showed in angiographic distribution of CAD, $46(92.0 \%)$ MAC cases and 39(78.0\%) controls had CAD. $17\left(34.0^{\circ} 7 \mathrm{o}\right)$ of patients with MAC and $16(32.0 \%)$ patients without MAC had single vessel disease, $8(16.0 \%)$ of patients with MAC and $12(24.0 \%)$ patients without MAC had double vessel disease, 2 1(42.0\%) of patients with MAC and $11(22.0 \%)$ patients without MAC had triple vessel disease (TVD), $8(16.0 \%)$ of patients with MAC and $2(4.0 \%)$ patients without MAC had Left main coronary artery disease and $4(8.0 \%)$ of patients with MAC and 1 1(22.0\%) patients without MAC had no CAD.

Table 1: Distribution of age by group

\begin{tabular}{|l|l|l|l|}
\hline Age $($ in years) & Case $(\mathbf{n}=\mathbf{5 0})$ & Control $(\mathbf{n}=50)$ & P Value \\
\hline$<45$ & $11(22.0)^{*}$ & $17(34.0)$ & 0.008 \\
\hline $45-60$ & $24(48.0)$ & $28(56.0)$ & \\
\hline$>6015$ & $(30.0)$ & $5(10.0)$ & \\
\hline Total & $50(100.0)$ & $50(100.0)$ & \\
\hline Mean \pm SD & $55.16 \pm 10.73$ & $49.80 \pm 8.84$ & \\
\hline
\end{tabular}

${ }^{*} t$ test was done to measure the level of significance.\#Figure within parentheses indicates in percentage.

Table 2: showed $82 \%$ of cases and $84 \%$ of controls were male, $18 \%$ of cases and $16 \%$ of controls were female, there was no significant sex difference between the two groups $(p=0.790)$.

\begin{tabular}{|l|l|l|l|}
\hline Sex & Case $(\mathbf{n}=\mathbf{5 0})$ & Control $(\mathbf{n}=50)$ & P Value \\
\hline Male & $41(82.0)$ & $42(84.0)$ & 0.790 \\
\hline Female & $9(18.0)$ & $8(16.0)$ & \\
\cline { 1 - 3 } & $50(100.0)$ & $50(100.0)$ & \\
\hline
\end{tabular}

${ }^{*}$ chi-square test was done to measure the level of significance. *Figure within parentheses indicates in percentage. 
Annals of International Medical and Dental Research

E-ISSN: 2395-2822 | P-ISSN: 2395-2814

Vol-8, Issue-2 | March-April 2022

DOI: 10.53339/aimdr.2022.8.2.24

Page no- 180-191 | Section- Research Article (Otolaryngology)

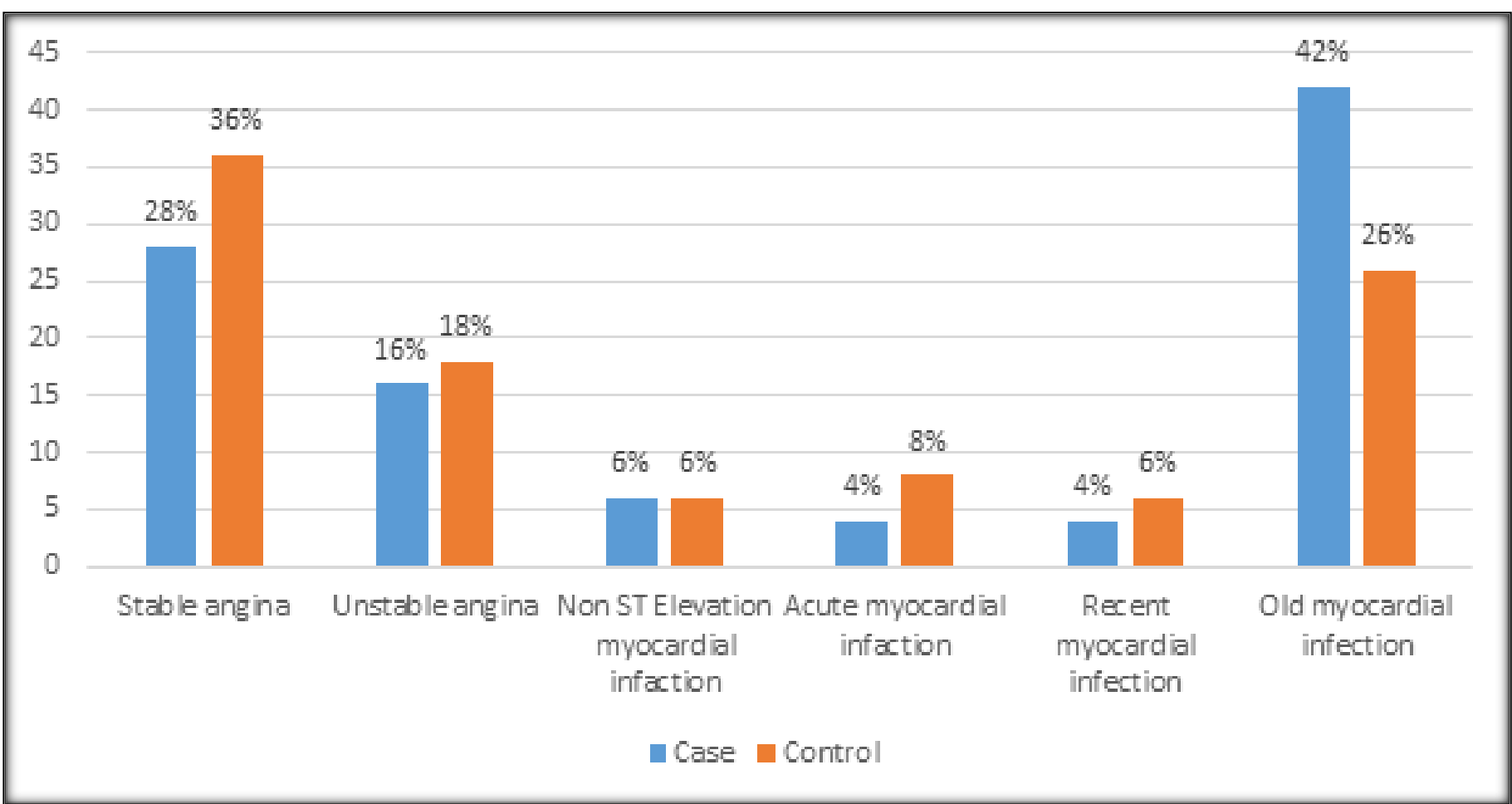

Figure 1: Bar diagram of clinical diagnosis by group

Table 3: Distribution of the patients by risk factors in two groups

\begin{tabular}{|l|l|l|l|}
\hline Risk Factor & Case & Control & P Value \\
\hline Smoking status & $32(64.0)$ & $33(66.0)$ & 0.834 \\
\hline Hypertension & $30(60.0)$ & $26(52.0)$ & 0.420 \\
\hline Diabetes & $24(48.0)$ & $11(22.0)$ & 0.006 \\
\hline History of renal disease & $4(8.0)$ & $2(4.0)$ & 0.400 \\
\hline
\end{tabular}

Table 4: Distribution of family history of different diseases

\begin{tabular}{|l|l|l|l|}
\hline Family history & Case $(\mathbf{n = 5 0})$ & Control $(\mathbf{n = 5 0})$ & P Value \\
\hline IITN & $9(18.0)$ & $0(.0)$ & $0.003^{* *}$ \\
\hline DM & $12(24.0)$ & $1(2.0)$ & $0.001^{*}$ \\
\hline CAD & $13(26.0)$ & $2(4.0)$ & $0.002^{*}$ \\
\hline
\end{tabular}

Table 5: Distribution of patients according to severity of MAC $(n=50)$

\begin{tabular}{|l|l|l|}
\hline Severity & $\mathbf{n = 5 0}$ & $\mathbf{\%}$ \\
\hline Mild & 15 & 30.0 \\
\hline Moderate & 11 & 22.0 \\
\hline Severe & 24 & 48.0 \\
\hline
\end{tabular}


Annals of International Medical and Dental Research E-ISSN: 2395-2822 | P-ISSN: 2395-2814

Vol-8, Issue-2 | March-April 2022

DOI: 10.53339/aimdr.2022.8.2.24

Page no- 180-191 | Section- Research Article (Otolaryngology)

Table 6: Distribution of CAD in patients with MAC

\begin{tabular}{|c|c|c|c|c|}
\hline \multicolumn{5}{|c|}{ MAC $(n=50)$} \\
\hline CAD & Mild & Moderate & Severe & Total \\
\hline SVD & $11(73.3)$ & $(45.5)$ & $1(4.2)$ & $17(34.0)$ \\
\hline DVD & $1(6.7)$ & $3(27.2)$ & $4(16.7)$ & $8(16.0)$ \\
\hline TVD & $0(.0)$ & $2(18.2)$ & $19(79.2)$ & $21(42.0)$ \\
\hline Normal & $3(20.0)$ & $1(9.1)$ & $0(.0)$ & $4(8.0)$ \\
\hline Total & $15(100.0)$ & $11(100.0)$ & $24(100.0)$ & $50(100.0)$ \\
\hline
\end{tabular}

Table 7: Distribution of severity of CAD by MAC

\begin{tabular}{|l|l|l|l|l|l|}
\hline \multicolumn{2}{|l|}{ MAC } & & & \\
\hline CAD & Severe & Not Severe & Total & r value & P value \\
\hline Severe & $19(79.2)$ & $2(7.7)$ & $21(42.0)$ & 0.723 & 0.001 \\
\hline Not severe & $5(20.8)$ & $24(92.3)$ & $29(58.0)$ & & \\
\cline { 1 - 3 } Total & $24(100.0)$ & $26(100.0)$ & $50(100.0)$ & & \\
\hline
\end{tabular}

Table 8: Characteristics of patients with and without Obstructive Coronary Artery Disease

\begin{tabular}{|c|c|c|c|}
\hline & \multicolumn{2}{|l|}{ CAD } & \multirow[b]{2}{*}{ P Value } \\
\hline & Positive $(n=85)$ & Negative $(n=15)$ & \\
\hline Age (in year) & $53.13 \pm 10.36$ & $48.80 \pm 8.15$ & $0.128 * *$ \\
\hline MAC & $46(54.1) *$ & $4(26.7)$ & 0.049 \\
\hline Hypercholesterolemia & $34(400)$ & $5(333)$ & 0.626 \\
\hline Smoking & $56(65.9)$ & $9(60.0)$ & 0.660 \\
\hline Hypertension & $47(553)$ & $9(60.0)$ & 0.735 \\
\hline Diabetes & $31(36.5)$ & $5(33.3)$ & 0.815 \\
\hline
\end{tabular}

Table 9: Prevalence of coronary artery disease in patients with MAC and without mitral annular calcification

\begin{tabular}{|l|l|l|l|}
\hline Comment & Case (MAC) $\mathbf{n = 5 0}(\boldsymbol{\%})$ & Control (Non-MAC) $\mathbf{n = 5 0}(\boldsymbol{\%})$ & P Value \\
\hline CAD & $46(92.0)^{*}$ & $39(78.0)$ & 0.049 \\
\hline SVD & $17(34.0)$ & $16(32.0)$ & 0.832 \\
\hline DVD & $8(16.0)$ & $12(24.0)$ & 0.317 \\
\hline TVD & $21(42.0)$ & $11(22.0)$ & 0.032 \\
\hline Left main & $8(16.0)$ & $2(4.0)$ & 0.046 \\
\hline Normal & $4(8.0)$ & $11(22.0)$ & 0.049 \\
\hline
\end{tabular}

\section{DISCUSSION}

Mitral annular calcification (MAC) is a degenerative process of the surrounding fibrous support of the mitral Valve.[18] Several previous pathologic and echocardiographic studies have demonstrated a strong association between MAC and risk factors such as age, male gender, hypertension, cholesterol, diabetes, and smoking. $[19,20]$ Previous studies 
Annals of International Medical and Dental Research

E-ISSN: 2395-2822 | P-ISSN: 2395-2814

Vol-8, Issue-2 | March-April 2022

DOI: 10.53339/aimdr.2022.8.2.24

Page no- 180-191 | Section- Research Article (Otolaryngology)

have also shown that patients with MAC undergoing coronary angiography have a higher prevalence of CAD. [20,21,22] The current study was carried out in fifty patients with MAC and fifty patients without MAC, to tests the hypothesis that mitral annular calcium (MAC) detected by transthoracic echocardiography (TTE) is a marker for high prevalence and severity of coronary artery disease (CAD) in patients undergoing coronary angiography. Current study Mean age of the case group was $55.16 \pm 10.73$ years and control group was $49.80 \pm 8.84$ years. In a similar study conducted by Adler mean age of case group was $71 \pm 8$ years and control group mean age was $70 \pm 6$ years (Adler et al, 1998). Eighty two percent of cases and $84 \%$ of control were male, $18 \%$ of cases and $16 \%$ of control were female, no significant sex difference between two groups. Willens et al, conducted study to determine whether the observed association between mitral annular calcification (MAC) and mortality independent of the severity of coronary artery disease (CAD), analyzed data from 134 male veterans (age $63 \pm 10$ years followed for 5 years who had undergone diagnostic coronary angiography and transthoracic echocardiography within 6 months of each other in their study mean BMI of MAC group was 28 and non-MAC group was 27.9. Among non MAC patients $34.9 \%$ were smoker and $28.6 \%$ MAC patients were smoker.[22] In our study $64 \%$ of cases and $66 \%$ of controls were smoker with no significant difference.Clinically among MAC and nonMAC patients $28 \%$ vs. $36 \%$ had stable angina, $16 . \%$ vs. $18 \%$ had unstable angina, $6 . \%$ vs. $6 . \%$ had non ST elevation myocardial infarction, $4 . \%$ vs. $8 . \%$ had acute myocardial infarction, $4 . \%$ vs. $6 . \%$ had recent myocardial infarction and $42 . \% \mathrm{vs} \quad 26 . \%$ had old myocardial infarction. In study by Adler et al, there was no significant difference between the MAC group and controls regarding reasons for referral for coronary angiography. Chest pain was the leading cause in both groups (41\% and 39\%), followed by anginal syndrome (32\% and 29\%), myocardial infarction (21\% and 29\%), and hemodynamic evaluations (7\% and 3\%) (Adler Ct al, 1998). In study by Atar et al, the patients' clinical characteristics are had no significant differences between the groups in terms of risk factors or clinical presentation $(71 \%$ of the control group and $79 \%$ of the index group had angina pectoris as an indication for angiography, $p=0.18$ ) Thirty five patients in the control group had undergone angiography for indications other thin chest pain or unstable angina, compared with 21 patients in the index group.[23] In the Framingham Heart Study ECG determinant left ventricular hypertrophy was found in 9.\% of MAC patients and 2.\% of nonMAC patients, MI was present in 5\% in both groups, atrial fibrillation in $12 . \%$ of MAC group and 5\% of non-MAC group (Fox et al, 2003). In our study ECG showed, Pathogical Q wave was found in $46 \%$, ST elevation in $4 \%$, ST change in $48 \%$ and normal in $2 \%$ of MAC positive patients. In non-MAC group Pathogical Q wave was found in $32 \%$, ST elevation in $8 \%$, ST change in 58\% and normal in $2 \%$. Transthoracic echocardiography revealed $52 \%$ of cases and $32 \%$ of controls had regional wall motion abnormalities (RWMA).

According to angiography, among MAC group $92 \%$ cases and among non- MAC controls $78 \%$ had coronary artery obstruction which is significantly higher in MAC group. In Adler et al, series $89 . \%$ of MAC group and $75 . \%$ of non- 
Annals of International Medical and Dental Research

E-ISSN: 2395-2822 | P-ISSN: 2395-2814

Vol-8, Issue-2 | March-April 2022

DOI: 10.53339/aimdr.2022.8.2.24

Page no- 180-191 | Section- Research Article (Otolaryngology)

MAC patients had angiographically proved coronary artery disease, ${ }^{[1]}$ which is very similar to our findings.In angiography CAD was present in $92 \%$ in patients with MAC and $78 \%$ without MAC. Single vessel disease was present in $34 \%$ of patients with MAC and $32 \%$ patients without MAC. Double vessel disease was present in $16 \%$ of patients with MAC and $24 \%$ patients without MAC. Triple vessel disease was present in $42 \%$ patients with MAC and $22 \%$ patients without MAC. Left main coronary artery disease was present in 16\% patients with MAC and $4 \%$ patients without MAC. Non-significant CAD was noted $8 \%$ patients with MAC and $22 \%$ without MAC. Atar et al., found significantly more obstructive coronary artery disease in patients in the MAC group than in the control group (88\% v 68\%, p $=0.0004)$. Patients in the index group had a higher prevalenceof significant left main coronary artery stenosis (16\% vs $4 \%, \mathrm{p}=0.046)$ and a higher prevalence of triple vessel coronary artery disease (42\% vs $22 \%$, p 0.032 ). The prevalence of double and single vessel disease was not different between the two groups.[23] In Adler et al study, 24\% patients MAC Vs $27 \%$ non-MAC patients had single vessel disease $20 \%$ patients MAC vs $26 \%$ non MAC had double vessel disease, $45 \%$ patients MAC vs. $24 \%$ non MAC had triple vessel disease and $13 \%$ patients MAC vs. $5 \%$ non MAC had left main CAD [18].Among 50 cases of $\mathrm{MAC}, 30 \%$ had mild MAC, $22 \%$ moderate and $48 \%$ had severe MAC. Among patients with SVD $73.3 \%$ had mild, $45.5 \%$ moderate and $4.2 \%$ had severe MACamong patients with DVD $6.7 \%$ had mild, $27.2 \%$ moderate and $16.7 \%$ had severe MAC Among patients with TVD none had mild, $18.2 \%$ had moderate and $79 \%$ had severe MAC. $20 \%$ without CAD had mild, 9.1\% had moderate and none had severe MAC.

Roberts et al showed that the same factors that predispose patients to atherosclerosis in the coronary arteries also predispose them to calcific deposits in the mitral annular region and the aortic valve cusps.[15] Patients who have hypercholesterolemia,[24] hypertension and diabetes mellitus exhibit a higher prevalence of MAC and aortic cusp calcification than patients who do not.15] In study of Atar et al, multivariate analysis found that hyperlipidaemia $(\mathrm{p}=0.002)$, mitral annular calcification 0.02), chest pain (p 0.02), smoking (p 0.05), age > 60 (p 0.04), and male sex ( $p$ 0.02) were independent predictors of the presence of significant coronary artery disease.[23] In the present study cardiac risk factors, only diabetes mellitus $(\mathrm{p}=0.001)$ emerged as a significant independent predictor for CAD, and it was significantly more prevalent in the MAC group, which is similar with study by Adler et al (1998). After we controlled for cardiac risk factors and reasons for cardiac angiography, multivariate analysis showed MAC as an independent predictor for CAD $\quad(p=0.049)$, Thus, transthorasic echocardiographically detected MAC will predict CAD in a high percentage of patients undergoing coronary angiography despite the absence of conventional coronary risk factors.

\section{Limitation of the study}

We do not know the exact prevalence of coronary artery disease, the sample for this study may not be representative of the general population. The selected patients were scheduled to undergo coronary angiography for a clinical indication; this inclusion criterion 
Annals of International Medical and Dental Research

E-ISSN: 2395-2822 | P-ISSN: 2395-2814

Vol-8, Issue-2 | March-April 2022

DOI: 10.53339/aimdr.2022.8.2.24

Page no- 180-191 | Section- Research Article (Otolaryngology)

might have skewed the spectrum of the population toward advanced forms of CAD. The higher percentage of male in the study is another limitation of the study. Involving equal ratios of both genders would have given us more representative idea.

\section{CONCLUSIONS}

Current study was carried out to evaluate the role of MAC detected by transthoracic echocardiography (TTE) as a predictor of

\section{REFERENCES}

1. Adler Y, Herz I, Vaturi M, Fusman R, ShohatZabarski R, Fink N, et al. Mitral annular calcium detected by transthoracic echocardiography is a marker for high prevalence and severity of coronary artery disease in patients undergoing coronary angiography. Am J Cardiol. 1998;82(10):1183-6. doi: 10.1016/s0002-9149(98)00596-7.

2. Korn D, Desanctis RW, Sell S. Massive calcification of the mitral annulus. A clinicopathological study of fourteen cases. N Engl J Med. 1962;267:900-9. doi: 10.1056/NEJM196211012671802.

3. Fulkerson PK, Beaver BM, Auseon JC, Graber HL. Calcification of the mitral annulus: etiology, clinical associations, complications and therapy. Am J Med. 1979;66(6):967-77. doi: 10.1016/0002-9343(79)90452-2.

4. Fox CS, Vasan RS, Parise H, Levy D, O'Donnell CJ, D'Agostino RB, et al; Framingham Heart Study. Mitral annular calcification predicts cardiovascular morbidity and mortality: the Framingham Heart Study. Circulation. 2003;107(11):1492-6. doi: 10.1161/01.cir.0000058168.26163.bc.

5. Libby P, Ridker PM, Maseri A. Inflammation and atherosclerosis. Circulation. 2002;105(9):1135-43. doi: 10.1161/hc0902.104353.

6. Tintut Y, Demer LL. Recent advances in multifactorial regulation of vascular calcification. Curr Opin Lipidol. 2001;12(5):555-60. doi: 10.1097/00041433-200110000-00012. coronary artery disease (CAD). This study found MAC as an independent predictor of coronary artery disease. This observation may provide a new tool useful for the cardiovascular risk stratification with standard transthorasic echocardiography. The low cost, portable and radiation free nature of the ultrasound approach make MAC an attractive parameter in the ongoing search which may be a reliable marker of coronary artery disease (CAD).

7. Demer LL. A skeleton in the atherosclerosis closet. Circulation. 1995;92(8):2029-32. doi: 10.1161/01.cir.92.8.2029.

8. Roberts WC. Morphologic features of the normal and abnormal mitral valve. Am J Cardiol. 1983;51(6):100528. doi: 10.1016/s0002-9149(83)80181-7.

9. Gardin JM, McClelland R, Kitzman D, Lima JA, Bommer W, Klopfenstein HS, et al. M-mode echocardiographic predictors of six- to seven-year incidence of coronary heart disease, stroke, congestive heart failure, and mortality in an elderly cohort (the Cardiovascular Health Study). Am J Cardiol. 2001;87(9):1051-7. doi: 10.1016/s00029149(01)01460-6.

10. Aronow WS, Ahn C, Kronzon I, Gutstein H. Association of mitral annular calcium with prior thromboembolic stroke in older White, AfricanAmerican, and Hispanic men and women. Am J Cardiol. 2000;85(5):672-3, A11. doi: 10.1016/s00029149(99)00835-8.

11. Adler Y, Shohat-Zabarski R, Vaturi M, Shapira Y, Ehrlich S, et al. Association between mitral annular calcium and aortic atheroma as detected by transesophageal echocardiographic study. Am J Cardiol. 1998;81(6):784-6. doi: 10.1016/s00029149(97)01014-x.

12. Greenland $\mathrm{P}$, Bonow RO, Brundage BH, Budoff MJ, Eisenberg MJ, Grundy SM, et al; American College of Cardiology Foundation Clinical Expert Consensus Task Force (ACCF/AHA Writing Committee to Update the 2000 Expert Consensus Document on Electron Beam Computed Tomography); Society of 
Annals of International Medical and Dental Research E-ISSN: 2395-2822 | P-ISSN: 2395-2814

Vol-8, Issue-2 | March-April 2022

DOI: 10.53339/aimdr.2022.8.2.24

Page no- 180-191 | Section- Research Article (Otolaryngology)

Atherosclerosis Imaging and Prevention; Society of Cardiovascular Computed Tomography. ACCF/AHA 2007 clinical expert consensus document on coronary artery calcium scoring by computed tomography in global cardiovascular risk assessment and in evaluation of patients with chest pain: a report of the American College of Cardiology Foundation Clinical Expert Consensus Task Force (ACCF/AHA Writing Committee to Update the 2000 Expert Consensus Document on Electron Beam Computed Tomography) developed in collaboration with the Society of Atherosclerosis Imaging and Prevention and the Society of Cardiovascular Computed Tomography. J Am Coll Cardiol. 2007;49(3):378-402. doi: 10.1016/j.jacc.2006.10.001.

13. Moe S, Drüeke $T$, Cunningham J, Goodman $W$, Martin K, Olgaard K, et al; Kidney Disease: Improving Global Outcomes (KDIGO). Definition, evaluation, and classification of renal osteodystrophy: a position statement from Kidney Disease: Improving Global Outcomes (KDIGO). Kidney Int. 2006;69(11):1945-53. doi: 10.1038/sj.ki.5000414.

14. Faggiano A, Santangelo G, Carugo S, Pressman G, Picano E, Faggiano P. Cardiovascular Calcification as a Marker of Increased Cardiovascular Risk and a Surrogate for Subclinical Atherosclerosis: Role of Echocardiography. J Clin Med. 2021;10(8):1668. doi:10.3390/jcm10081668

15. Roberts WC. The senile cardiac calcification syndrome. Am J Cardiol. 1986;58(6):572-4. doi: 10.1016/0002-9149(86)90045-7.

16. Nair CK, Thomson W, Ryschon K, Cook C, Hee TT, Sketch MH. Long-term follow-up of patients with echocardiographically detected mitral anular calcium and comparison with age- and sex-matched control subjects. Am J Cardiol. 1989;63(7):465-70. doi: 10.1016/0002-9149(89)90321-4.

17. Aronow WS, Koenigsberg M, Kronzon I, Gutstein H. Association of mitral anular calcium with new thromboembolic stroke and cardiac events at 39month follow-up in elderly patients. Am J Cardiol.
1990;65(22):1511-2. doi: 10.1016/0002-9149(90)91364-

c.

18. Adler Y, Koren A, Fink N, Tanne D, Fusman R, Assali $\mathrm{A}$, et al. Association between mitral annulus calcification and carotid atherosclerotic disease. Stroke. 1998;29(9):1833-7. doi: 10.1161/01.str.29.9.1833.

19. Tolstrup K, Roldan CA, Qualls CR, Crawford MH. Aortic valve sclerosis, mitral annular calcium, and aortic root sclerosis as markers of atherosclerosis in men. Am J Cardiol. 2002;89(9):1030-4. doi: 10.1016/s0002-9149(02)02270-1.

20. Movahed MR, Saito Y, Ahmadi-Kashani M, Ebrahimi R. Mitral annulus calcification is associated with valvular and cardiac structural abnormalities. Cardiovasc Ultrasound. 2007;5:14. doi: 10.1186/14767120-5-14.

21. Jean G, Bresson E, Terrat JC, Vanel T, Hurot JM, Lorriaux $\mathrm{C}$, et al. Peripheral vascular calcification in long-haemodialysis patients: associated factors and survival consequences. Nephrol Dial Transplant. 2009;24(3):948-55. doi: 10.1093/ndt/gfn571.

22. Willens HJ, Chirinos JA, Schob A, Veerani A, Perez AJ, Chakko S. The relation between mitral annular calcification and mortality in patients undergoing diagnostic coronary angiography. Echocardiography. 2006;23(9):717-22. doi: 10.1111/j.15408175.2006.00300.x.

23. Atar S, Jeon DS, Luo H, Siegel RJ. Mitral annular calcification: a marker of severe coronary artery disease in patients under 65 years old. Heart. 2003;89(2):161-4. doi: 10.1136/heart.89.2.161.

24. Sprecher DL, Schaefer EJ, Kent KM, Gregg RE, Zech LA, Hoeg JM, McManus B, Roberts WC, Brewer HB Jr. Cardiovascular features of homozygous familial hypercholesterolemia: analysis of 16 patients. Am J Cardiol. 1984;54(1):20-30. doi: 10.1016/00029149(84)90298-4.

Source of Support: Nil, Conflict of Interest: None declared 